\title{
Healed bite marks on a Cretaceous ichthyosaur
}

\author{
Maria Zammit and Benjamin P. Kear \\ Acta Palaeontologica Polonica 56 (4), 2011: 859-863 doi: http://dx.doi.org/10.4202/app.2010.0117
}

Reports of pathological ichthyosaur fossils are very rare. The identification of a series of healed cuts and an associated gouge on the lower jaw of an adult (ca. 5 metres body length) Platypterygius specimen from the Lower Cretaceous of Australia is therefore significant, because it constitutes direct evidence of bite force trauma sustained during the life of the animal. Based on the close spacing and non-lethal facial positioning of the wounds, they were probably not inflicted by a predator. Alternative explanations might include an accidental aggressive encounter with another large vertebrate, or perhaps an intraspecific interaction such as during courtship or combat over food, mates, or territory.

Maria Zammit [maria.zammit@adelaide.edu.au], School of Earth and Environmental Sciences, North Terrace Campus, University of Adelaide, Adelaide, South Australia, Australia 5005; Benjamin P. Kear [Benjamin.kear@geo.uu.se], Palaeobiology Programme, Department of Earth Sciences, Uppsala University, Villavägen 16, SE-752 36 Uppsala, Sweden.

This is an open-access article distributed under the terms of the Creative Commons Attribution License (for details please see creativecommons.org), which permits unrestricted use, distribution, and reproduction in any medium, provided the original author and source are credited. 